\title{
Identification of JAK2 As a Growth Hormone Receptor-Associated Tyrosine Kinase
}

\author{
Lawrence S. Argetsinger, " George S. Campbell, * \\ Xianjie Yang, † Bruce A. Witthuhn, $\neq$ \\ Olli Silvennoinen, $\neq$ James $N$. Ihle, $\neq$ \\ and Christin Carter-Su* \\ *Department of Physiology \\ University of Michigan Medical School \\ Ann Arbor, Michigan 48109 \\ tDepartment of Genetics \\ Harvard Medical School \\ Boston, Massachusetts 02115 \\ tDepartment of Biochemistry \\ St. Jude Children's Research Hospital \\ Memphis, Tennessee 38105
}

\section{Summary}

Growth hormone receptor (GHR) forms a complex with a tyrosine kinase, suggesting involvement of a ligandactivated tyrosine kinase in intracellular signaling by growth hormone (GH). Here we identify JAK2, a nonreceptor tyrosine kinase, as a GHR-associated tyrosine kinase. Immunological approaches were used to establish GH-dependent complex formation between JAK2 and GHR, activation of JAK2 tyrosine kinase activity, and tyrosyl phosphorylation of both JAK2 and GHR. The JAK2-GHR and JAK2-erythropoietin receptor interactions described here and in the accompanying paper provide a molecular basis for involvement of tyrosyl phosphorylation in physiological responses to these ligands and suggest a shared signaling mechanism among members of the cytokine/hematopoietin receptor family.

\section{Introduction}

Although the ability of growth hormone $(\mathrm{GH})$ to promote growth and regulate metabolism has been known for many years (Cheek and Hill, 1974; Davidson, 1987), the molecular mechanism by which GH binding to its receptor elicits its diverse responses has remained an enigma. New insight into GH signaling mechanisms was recently provided by the demonstration that a tyrosine kinase is present in a complex with $\mathrm{GH}$ receptor (GHR) prepared from $\mathrm{GH}$ treated cells (Carter-Su et al., 1989; Stred et al., 1992; Wang et al., 1992). Additional studies in 3T3-F442A cells showing rapid GH-dependent tyrosyl phosphorylation of multiple proteins, tyrosyl phosphorylation of microtubuleassociated protein kinases, and stimulation of microtubule-associated protein kinase activity, as well as the inhibition of these actions by inhibitors of the GHR-associated tyrosine kinase (Campbell et al., 1993), suggest a central role for a GHR-associated tyrosine kinase in signaling by GH. Recently, a nonreceptor tyrosyl phosphorylated 121 kd protein was identified in a kinase-active GH-GHR preparation (Wang et al., 1993). Since autophosphorylation is often a manifestation of an activated kinase, it was hypoth- esized that this $121 \mathrm{kd}$ phosphoprotein is the GHRassociated kinase.

In this study, we identify JAK2, a 130 kd tyrosine kinase (Silvennoinen et al., 1993; Harpur et al., 1992), as a GHRassociated kinase. JAK2 is a member of the recently described Janus family of tyrosine kinases consisting of JAK1, JAK2, and Tyk2. In addition to having a kinase domain, these proteins are characterized by the presence of a second kinase-like domain and the absence of Src homology 2 (SH2), SH3, and membrane-spanning domains (Wilks et al., 1991; Firmbach-Kraft et al., 1990; Harpur et al., 1992; Silvennoinen et al., 1993). Members of the JAK family were thought to be good candidates for the GHR-associated tyrosine kinase because of their size $\left(M_{r}\right.$ of $\left.\sim 130,000\right)$, their presence in GH-responsive tissues, and the ability of Tyk2 to serve as a signaling molecule for the interferon $\alpha / \beta$ (IFN- $\alpha / \beta$ ) receptor, a receptor distantly related to GHR (Harpur et al., 1992; Silvennoinen et al., 1993; Wilks et al., 1991; Firmbach-Kraft et al., 1990; Bazan, 1990; Velazquez et al., 1992). Here we show that GH binding promotes association of JAK2 with GHR, activation of JAK2, and tyrosyl phosphorylation of both JAK2 and GHR. The identification of JAK2 as a signaling molecule early in the GHR signal transduction pathway provides important insight into signaling by GHR and into the function of JAK2. Work presented in the accompanying paper (Witthuhn et al., 1993 [this issue of Cel/]) indicates that JAK2 also associates with the receptor for erythropoietin (EPO), and other data indicate that at least four other members of the cytokine/hematopoietin receptor family (receptors for interleukin [IL]-3), granulocyte-macrophage colony-stimulating factor [GM-CSF], granulocyte colonystimulating factor [G-CSF], and prolactin) and the more distantly related IFN-y receptor activate JAK2 (Silvennoinen et al., 1993; Witthuhn et al., 1993; O. S. et al., unpublished data; G. S. C. et al., unpublished data). It therefore seems likely that the JAK2-GHR and JAK2EPO receptor interactions shown in this paper and by Witthuhn et al. (1993) will serve as prototypes for signaling through many members of this large receptor superfamily.

\section{Results}

\section{GH Stimulates Tyrosyl Phosphorylation of JAK2}

On the basis of previous studies establishing the existence of a GHR-associated tyrosine kinase (Carter-Su et al., 1989; Stred et al., 1992; Wang et al., 1993; Campbell et al., 1993), the GHR-associated tyrosine kinase would be expected: first, to be a protein of $\sim 120 \mathrm{kd}$; second, to be tyrosyl phosphorylated in response to $\mathrm{GH}$; third, to be present in a complex with GHR; and fourth, to exhibit increased activity in response to $\mathrm{GH}$.

JAK2 is a tyrosine kinase of the correct size $\left(\mathrm{Mr}_{\mathrm{r}}\right.$ of $\sim 130,000$; Silvennoinen et al., 1993) to be the GHRassociated kinase and was therefore tested for its ability to be phosphorylated in response to $\mathrm{GH}$. Solubilized proteins from GH-treated 3T3-F442A fibroblasts were immunopre- 
A

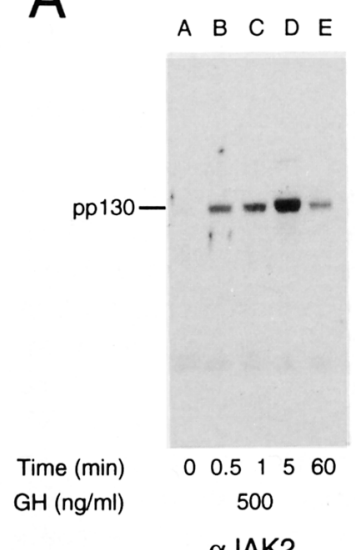

oJAK2

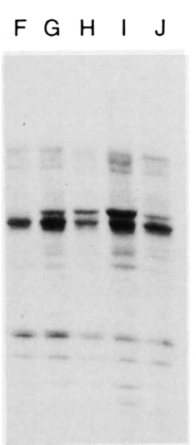

00.51560 500

Lysate

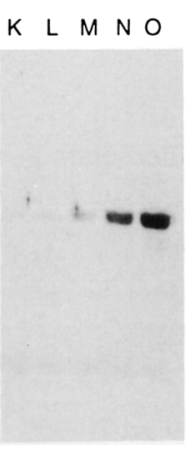

5

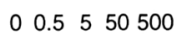

QJAK2

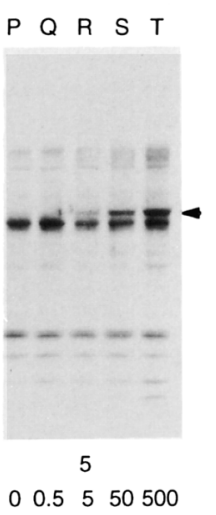

Lysate

B

C
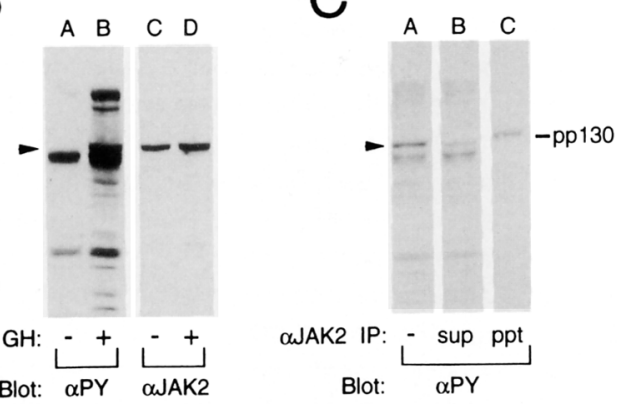

cipitated using antiserum to JAK2 ( $\alpha$ JAK2) and analyzed by anti-phosphotyrosine antibody ( $\alpha$ PY) immunoblot (Figure 1A). GH-dependent tyrosyl phosphorylation of a protein with an $\mathrm{M}_{\mathrm{r}}(\sim 130,000)$ appropriate for JAK2 (Silvennoinen et al., 1993) was clearly evident at times as early as $30 \mathrm{~s}$ and at physiological concentrations of $\mathrm{GH}$ as low as $5.0 \mathrm{ng} / \mathrm{ml}$ (230 pM). Phosphorylation was transient, being greatly diminished by $60 \mathrm{~min}$ after addition of $\mathrm{GH}$. The appearance of the $130 \mathrm{kd}$ phosphoprotein in $\alpha P Y$ immunoblots of $\alpha \mathrm{JAK} 2$ immunoprecipitates (Figure 1A, lanes $\mathrm{A}-\mathrm{E}$ and $\mathrm{K}-\mathrm{O}$ ) corresponds in time course and $\mathrm{GH}$ dose response with the appearance in whole-cell lysates of a tyrosyl-phosphorylated protein, indicated by the arrow in Figure 1A (lanes $F-J$ and $P-T$ ) and designated pp121 in previous work (Campbell et al., 1993; Wang et al., 1993). The identity of these two proteins is suggested by the comigration in cell lysates of tyrosyl phosphorylated pp121 and JAK2 (Figure 1B) and the depletion of tyrosyl-phosphorylated pp121 from cell lysates following immunoprecipitation with aJAK2 (Figure 1C).

The $130 \mathrm{kd}$ phosphoprotein was precipitated specifically by aJAK2 (Figures $2 A$ and $2 B$, lanes $B$ ). Nonimmune serum (Figure 2A, lane $A$ ), an unrelated immune serum (aGLUT-1; Figure 2A, lane C), and aJAK2 preadsorbed with the peptide used to make the antibody (Figure 2B, lane D) failed to immunoprecipitate pp130. Preadsorption of $\alpha$ JAK2 with the analogous peptide from murine JAK1 (Silvennoinen et al., 1993) did not interfere with precipita-

Figure 1. GH Promotes Tyrosyl Phosphorylation of JAK2

(A) 3T3-F442A fibroblasts were incubated with the indicated concentrations of hGH for the times shown. Whole-cell lysates were immunoprecipitated with a.JAK2 (1:500 dilution). Immunoprecipitated proteins (lanes A-E and $\mathrm{K}-\mathrm{O}$ ) and unfractionated lysates (lanes $F-J$ and $P-T$ ) were subjected to Western blot analysis using aPY-4G10. The decreased intensity of all the bands in lane $\mathrm{H}$ in comparison with the bands in the other lanes (including the $O$ time point) suggests that lane $H$ contains proteins from fewer cells than the other lanes.

(B) Whole-cell lysates of 3T3-F442A fibroblasts incubated without (lanes $A$ and $C$ ) or with (lanes $B$ and D) $500 \mathrm{ng} / \mathrm{ml} \mathrm{hGH}$ for $5 \mathrm{~min}$ were subjecied to Western blot analysis with either aPY-4G10 (lanes A and B) or aJAK2 (lanes C and $D$ ).

(C) Cell lysates from 3T3-F442A fibroblasts stimulated with $500 \mathrm{ng} / \mathrm{ml} \mathrm{hGH}$ for $5 \mathrm{~min}$ were immunoprecipitated with $\alpha$ JAK2 $(1: 1000)$ and Western blotted with $\alpha P Y-4 G 10$. Lane A, total lysate; lane B, supernatant following immunoprecipitation with oJAK2; lane C, aJAK2 immunoprecipitate. All lanes represent equivalent amounts of cell lysate. When assessed by densitometry, the amount of pp121 removed by the aJAK2 treatment is found to be equal (within $5 \%$ ) to the amount of tyrosyl-phosphorylated protein appearing in the $\alpha$ JAK2 immunoprecipitate. The migration of pp121 in whole-cell lysates is denoted by the arrow. The migration of pp130 is denoted.

tion of the $130 \mathrm{kd}$ phosphoprotein by aJAK2 (Figure 2B, lane $F$ ). In contrast with these results using aJAK2, immunoprecipitation of 3T3-F442A and IM-9 cell lysates, respectively, with antibodies specific for JAK1 (aJAK1) and Tyk2 ( $\alpha$ Tyk2) revealed little ( $\alpha$ JAK1) or no ( $\alpha$ Tyk2) GHdependent tyrosyl phosphorylation of a $\sim 130 \mathrm{kd}$ protein, despite the presence of these kinases in the respective cell types (data not shown).

Tyrosyl phosphorylation of the $130 \mathrm{kd}$ protein precipitated from 3T3-F442A cells by aJAK2 was increased specifically by $\mathrm{GH}$. Phosphorylation was not increased by platelet-derived growth factor, epidermal growth factor, or insulin-like growth factor 1 (Figure 2A, lanes E-G, respectively). These growth factors stimulate tyrosine kinase activity intrinsic to their receptors (Ullich and Schlessinger, 1990) and promote tyrosyl phosphorylation of multiple proteins in 3T3-F442A fibroblasts (Campbell et al., 1993). The inability to stimulate JAK2 tyrosyl phosphorylation is consistent with the previously reported inability of these growth factors to stimulate tyrosyl phosphorylation of pp121 in whole-cell lysates (Campbell et al., 1993).

\section{JAK2 Assoclates with the GH Receptor}

To determine whether JAK2 forms a complex with GHR, GH-GHR complexes and associated proteins were immunoprecipitated from solubilized, GH-treated 3T3-F442A fibroblasts using antibody to $\mathrm{GH}(\alpha \mathrm{GH})$. The presence of JAK2 in $\alpha$ GH immunoprecipitates was assessed either by 


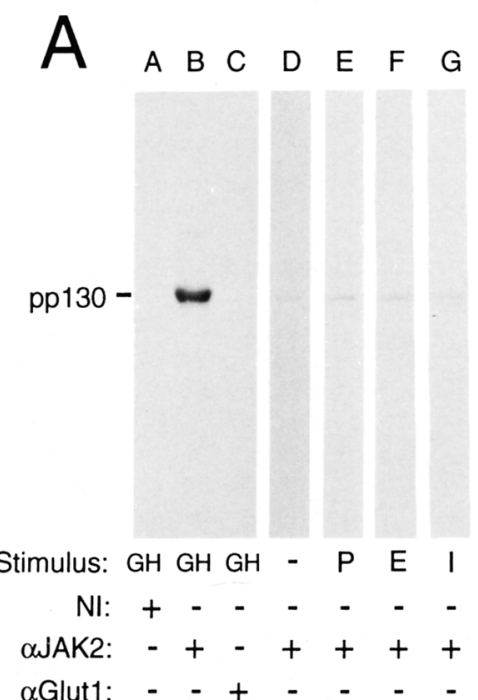

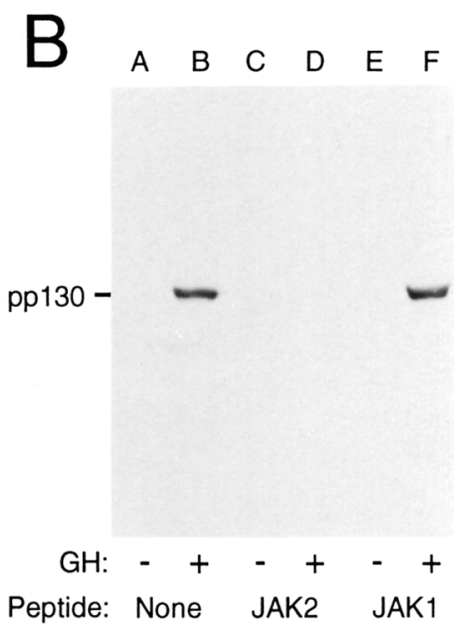

Figure 2. Tyrosyl Phosphorylation of JAK2 Is Specific to GH Stimulation

(A) Cell lysates from unstimulated 3T3-F442A fibroblasts (lane D) and from cells stimulated for $5 \mathrm{~min}$ with $500 \mathrm{ng} / \mathrm{ml} \mathrm{hGH}$ (lanes A-C), 25 $\mathrm{ng} / \mathrm{ml}$ platelet-derived growth factor (lane E), $125 \mathrm{ng} / \mathrm{ml}$ epidermal growth factor (lane $\mathrm{F}$ ), or $200 \mathrm{ng} / \mathrm{ml}$ insulin-like growth factor 1 (lane G) were subjected to immunoprecipitation with aJAK2 (1:1000; lanes B and D-G), nonimmune serum (1:1000; lane $A)$, or an irrelevant antise rum ( $\alpha$ GLUT-1, 1:1000; lane $C$ ) (Tai et al. 1990), as described in Figure 1. The immunoprecipitates were analyzed by Western blot analysis with $A P Y-4 G 10$.

(B) Cell lysates from unstimulated 3T3-F442A fibroblasts (lanes $A, C$, and $E$ ) and from cells stimulated for 5 min with $500 \mathrm{ng} / \mathrm{ml}$ hGH (lanes $B, D$, and $F$ were subjected to immunoprecipitation with aJAK2 (1:1000; lanes $A$ and $B)$ aJAK2 (1:1000) that had been preincubated for $1 \mathrm{hr}$ at $0^{\circ} \mathrm{C}$ with the peptide $(30 \mu \mathrm{g} / \mathrm{ml})$ used as antigen to make aJAK2 (lanes $\mathrm{C}$ and D; Silvennoinen et al., 1993) or a peptide analogous to amino acids 785-804 of JAK1 (lanes E and F; Silvennoinen et al., 1993). immunoblotting with aJAK2 or by immunoprecipitating with $\alpha J A K 2$ and immunoblotting with $\alpha P Y$. When material precipitated using $\alpha \mathrm{GH}$ was analyzed, aJAK2 was found to immunoblot a $130 \mathrm{kd}$ protein (Figure 3, lane B) and to immunoprecipitate a tyrosyl-phosphorylated $130 \mathrm{kd}$ protein (Figure 3, lane $L$ ) that comigrates with a protein recognized by aJAK2 (Figure 3, lane M), indicating that JAK2 associates with GH-GHR complexes. When instead of $\alpha \mathrm{GH}$, the initial immunoprecipitation was performed with antibody to either the cytoplasmic (Figure 3, lanes $C$ and D) or extracellular (data not shown) domains of GHR ( $\alpha \mathrm{GHR}$ ), aJAK2 recognized a $130 \mathrm{kd}$ protein only when cells had been incubated with $\mathrm{GH}$. Consistent with the presence of JAK2 in the $\alpha$ GHR precipitate because of its association with GH-bound GHR, no signal was detected in aJAK2 immunoblots of $\alpha \mathrm{GH}$ immunoprecipitates when cells had not been incubated with GH (Figure 3, lane A) nor when immunoprecipitation was performed using an unrelated immune serum ( $\alpha$ GLUT-1) (data not shown). These results provide evidence that $\mathrm{GH}$ binding to its receptor is necessary for the formation of a complex between GHR and JAK2.

In addition to the $130 \mathrm{kd}$ phosphoprotein believed to be JAK2, a diffusely migrating phosphoprotein of $\sim 120 \mathrm{kd}$ identified by $\alpha P Y$ immunoblot was precipitated by $\alpha \mathrm{GH}$ (Figure 3, lanes F and J), aGHR (Figure 3, lane H), and to a lesser extent aJAK2 (Figure 3, lane K). Consistent with this diffuse band being GHR, its size corresponds to that previously reported for GHR in these cells (Schwartz and Carter-Su, 1988; Stred et al., 1992), and it comigrates with a similarly diffuse $-120 \mathrm{kd}$ band identified by $\alpha \mathrm{GHR}$ in Western blots of $\alpha \mathrm{GH}$ immunoprecipitates (Figure 3 ,

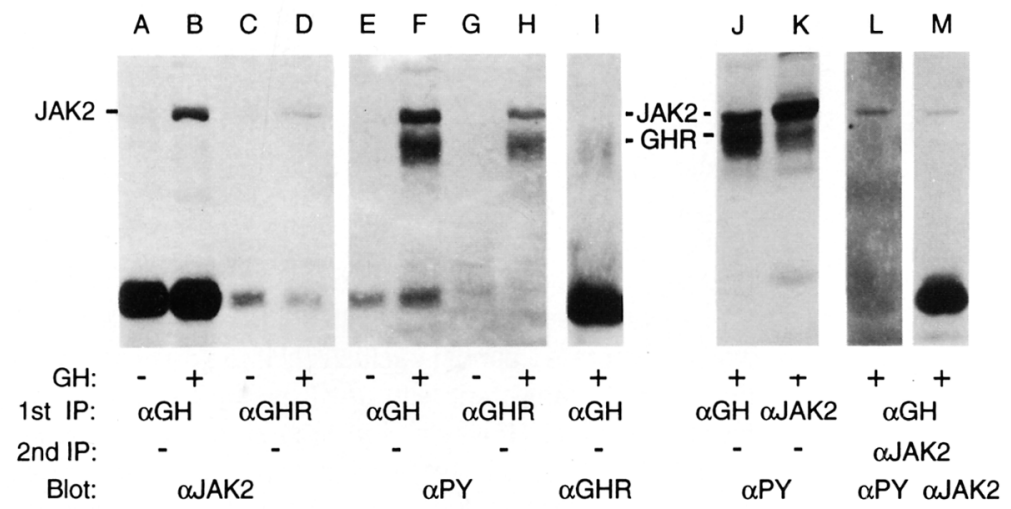

Figure 3. GH Promotes Complex Formation between GHR and JAK2 and Promotes Tyrosy Phosphorylation of GHR and JAK2

3T3-F442A fibroblasts were incubated with vehicle (lanes A, C, E, and G) or $500 \mathrm{ng} / \mathrm{ml} \mathrm{hGH}$ (tanes B, D, F, and H-M) for $5 \mathrm{~min}$. Solubilized proteins were immunoprecipitated using $\alpha \mathrm{GH}$ (1:4000; lanes A, B, E, F, I, J, L, and M), aGHR C1 $(\sim 0.1 \mu \mathrm{g} / \mathrm{ml}$; lanes $\mathrm{C}, \mathrm{D}, \mathrm{G}$, and $\mathrm{H})$, or aJAK2 (1:1000; lane K). The precipitated proteins were subjected to Western blotting using aJAK2 (lanes A-D), aPY-4G10 (lanes E-H, J, and $\mathrm{K})$ or $\alpha \mathrm{GHA}-\mathrm{C1}(\sim 0.1 \mu \mathrm{g} / \mathrm{ml}$; lane I). For the samples for lanes $L$ and $M$, the precipitate was washed and boiled in buffer containing SDS, $\beta$-mercaptoethanol, and DTT, as described in Experimental Procedures. Samples were diluted 10-fold with lysis buffer, immunoprecipitated with aJAK2 (1:1000), and Western blotted using aPY-4G10 (lane L) or aJAK2 (lane M). Lanes $A-H$ are from one experiment, lane $I$ from a second, lanes $J$ and $K$ from a third, and lanes $L$ and $M$ from a fourth. The migrations of $J A K 2$ and GHR are indicated. 


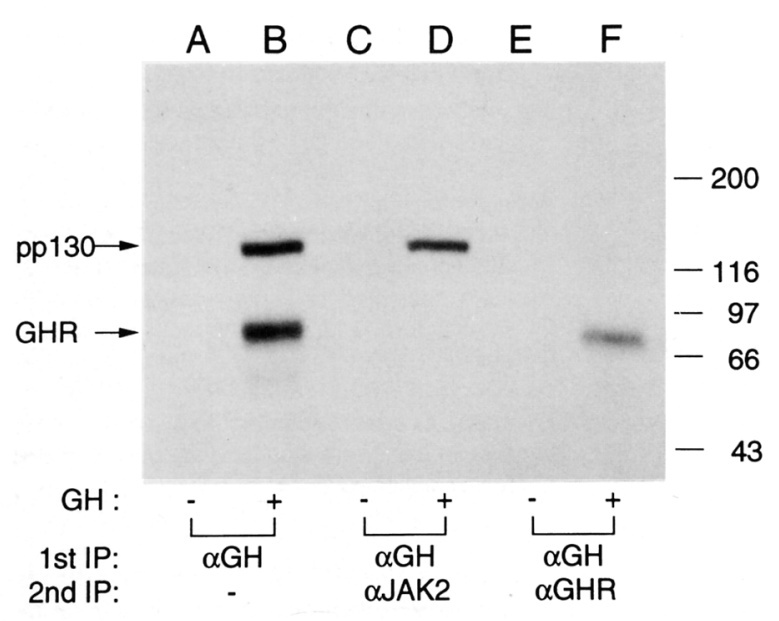

Figure 4. JAK2 Is Associated with GHR and Is Phosphorylated in Vitro $\mathrm{CHO} 4$ cells were incubated at $25^{\circ} \mathrm{C}$ in the absence (lanes $\mathrm{A}, \mathrm{C}$, and E) or presence (lanes B, D, and F) of $30 \mathrm{ng} / \mathrm{ml} \mathrm{hGH}$ for $60 \mathrm{~min}$. Cellular proteins were solubilized, immunoprecipitated using $\alpha \mathrm{GH}$, and incubated with [ $\gamma{ }^{-32}$ ] ]ATP. Immune complexes and associated proteins were treated with SDS, $\beta$-mercaptoethanol, and DTT. The dissociated proteins were diluted. Samples were then removed for analysis by SDS-PAGE (150 $\mu \mathrm{l}$; lanes A and B) or reimmunoprecipitated $(550 \mu \mathrm{l})$ with $\alpha$ JAK2 (lanes $C$ and D) or $\alpha$ GHR ( $\alpha$ GHBP-poly; lanes $E$ and $F$ ) as described in Experimental Procedures. ${ }^{32} \mathrm{P}$-labeled proteins were resolved by SDS-PAGE and visualized by autoradiography. The molecular weight $\left(\times 10^{-3}\right)$ of protein standards and the migration of pp130 and GHR are indicated.

lane I). The finding that tyrosyl residues are phosphorylated in the diffuse $120 \mathrm{kd}$ protein present in aGHR immunoprecipitates only when the cells have been incubated with $\mathrm{GH}$ (Figure 3 , lanes $\mathrm{G}$ and $\mathrm{H}$ ) offers evidence that tyrosyl phosphorylation of GHR, like tyrosyl phosphorylation of JAK2, is GH dependent. Additional evidence that both JAK2 and GHR are tyrosyl phosphorylated in response to $\mathrm{GH}$ is provided by the finding that in a transfected Chinese hamster ovary cell line $(\mathrm{CHO})$ that expresses a smaller (84 kd) GHR (Emtner et al., 1990; Wang et al., 1993), tyrosyl phosphorylation of a $130 \mathrm{kd}$ protein in $\alpha \mathrm{GH}, \alpha \mathrm{GHR}$, and $\alpha \mathrm{JAK} 2$ immunoprecipitates and a diffusely migrating $84 \mathrm{kd}$ protein in $\alpha \mathrm{GH}$ and $\alpha \mathrm{GHR}$ immunoprecipitates is GH dependent (data not shown).

\section{Stimulation by GH of JAK2 Kinase Activity}

Previous studies have established that when $\alpha \mathrm{GH}$ precipitates are prepared from $\mathrm{GH}$-treated $\mathrm{CHO} 4$ cells, the addition of ATP results in the tyrosyl phosphorylation of both a $130 \mathrm{kd}$ and a $84 \mathrm{kd}$ protein (Wang et al., 1993). To determine whether the $130 \mathrm{kd}$ and $84 \mathrm{kd}$ proteins phosphorylated in this in vitro kinase assay are JAK2 and GHR, respectively, GH-GHR complexes and associated proteins were precipitated from $\mathrm{GH}$-treated $\mathrm{CHO} 4$ cells using $\alpha \mathrm{GH}$, incubated with [ $\gamma$ - ${ }^{32}$ P]ATP, dissociated by boiling in buffer containing SDS, $\beta$-mercaptoethanol, and dithiothreitol (DTT), and reprecipitated using either aJAK2 or $\alpha \mathrm{GHR}$. The ability of aJAK2 to precipitate a $130 \mathrm{kd}{ }^{32} \mathrm{P}$-labeled

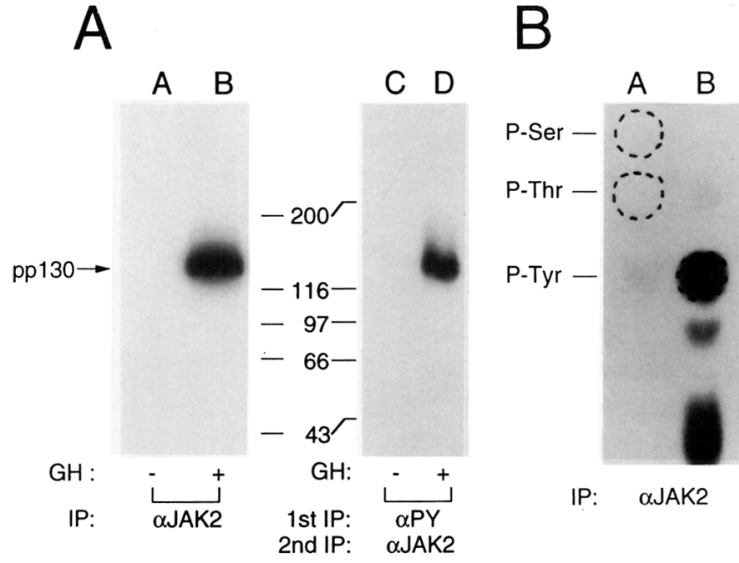

Figure 5. Purified JAK2 Possesses Tyrosine Kinase Activity

(A) 3T3-F442A cells were incubated at $25^{\circ} \mathrm{C}$ in the absence (lanes $A$ and C) or presence (lanes B and D) of $30 \mathrm{ng} / \mathrm{ml} \mathrm{hGH}$ for $1 \mathrm{hr}$. Solubilized proteins were immunoprecipitated using a.JAK2 (lanes A and B) or sequentially immunoprecipitated using first aPY and then aJAK2 (lanes $C$ and D) and incubated with [ $\gamma$ - $\left.{ }^{32} P\right] A T P$ as described in Experimental Procedures. The molecular weight $\left(\times 10^{-3}\right)$ of protein standards and migration of $p p 130$ are indicated.

(B) pp130 was excised from the gel visualized in lane B of (A) and subjected to limited acid hydrolysis at $109^{\circ} \mathrm{C}$ for $1.25 \mathrm{hr}$. Following partial purification on Dowex-50, fractions containing O-phosphoserine and O-phosphothreonine (lane A) or O-phosphotyrosine (lane B) were resolved by thin layer electrophoresis ( $\mathrm{pH} 3.5)$ as previously described (Carter-Su et al., 1989; Stred et al., 1990; Wang et al., 1992). The migrations of O-phosphoserine (P-Ser), O-phosphothreonine (P-Thr), and O-phosphotyrosine (P-Tyr) standards are indicated by the dashed circles.

protein appropriate for JAK2 (Figure 4, lane D), as well as the ability of aGHR to precipitate an $84 \mathrm{kd}{ }^{32} \mathrm{P}$-labeled protein appropriate for GHR (Figure 4, lane F), indicates that both JAK2 and GHR incorporate ${ }^{32 P}$ in the in vitro kinase assay.

To verify that JAK2 functions as a GH-dependent tyrosine kinase, JAK2 was purified from GH-treated and control 3T3-F442A cells either by direct immunoprecipitation with aJAK2 (Figure 5A, lanes A and B) or, to permit a higher degree of purification, by sequential immunoprecipitation using $\alpha P Y$ followed by $\alpha$ JAK2 (Figure $5 A$, lanes $C$ and $D$ ). When the aJAK2 immune complexes were incubated with $\left[\gamma-{ }^{32} \mathrm{P}\right] A T P,{ }^{32} \mathrm{P}$-labeled proteins migrating with a $\mathrm{M}_{\mathrm{r}}$ $(130,000)$ appropriate for JAK2 were detected only when the cells had been incubated with GH (Figure 5A, lanes $B$ and D), indicating an exquisite sensitivity of JAK2 to activation by GH. To verify that JAK2 incorporates phosphate into tyrosyl residues, phosphoamino acid analysis was performed on the ${ }^{32} \mathrm{P}$-labeled $130 \mathrm{kd}$ protein isolated from GH-treated 3T3-F442A cells (Figure 5A, lane B). ${ }^{32} \mathrm{P}$ was incorporated almost exclusively into tyrosyl residues (Figure 5B), consistent with JAK2 being a GH-sensitive tyrosine kinase. However, the incorporation of a small amount of ${ }^{32} \mathrm{P}$ (under $1 \%$ ) into threonine residues in the aJAK2 immunoprecipitate leaves open the possibility that JAK2 is a mixed function threonine/serine/tyrosine kinase. 


\section{Discussion}

\section{Identification of JAK2 As a Signaling Molecule for GHR}

The identification of JAK2 as a GH-dependent, GHRassociated tyrosine kinase has important implications for signal transduction by both GHR and JAK2. With regard to GHR, JAK2 is identified as a signaling molecule that interacts with GHR and is activated in response to $\mathrm{GH}$ binding. Its sensitivity to $\mathrm{GH}$ and rapid onset following $\mathrm{GH}$ addition make tyrosyl phosphorylation of JAK2 among the most sensitive and rapid responses known for $\mathrm{GH}$, raising the possibility that activation of JAK2 is the initiating step for GH signal transduction. Tyrosine kinases have been shown to elicit responses similar to those attributable to $\mathrm{GH}$, including metabolic responses (e.g., insulin receptor) and differentiation (e.g., nerve growth factor receptor) (reviewed by Davidson, 1987; Isaksson et al., 1987; LeviMontalcini, 1987; Kaplan et al., 1991). Therefore, it seems likely that JAK2 plays a vital role in eliciting at least some of the known responses to $\mathrm{GH}$. Consistent with this, no biological functions, other than binding of $\mathrm{GH}$, have been reported for GHR expressed in cells that have low levels of GHR-associated tyrosine kinase activity (e.g., COS-7 and mouse L cells; Leung et al., 1987; Wang et al., 1992, and unpublished data). In contrast, a variety of biological functions (e.g., insulin synthesis in RIN5-AH cells and protein synthesis, microtubule-associated protein kinase activity, c-fos gene expression, and lipid synthesis in Chinese hamster ovary cells) can be activated by $\mathrm{GH}$ binding when the cloned liver GHR is expressed in cells that have reasonably high levels of GHR-associated kinase activity (Billestrup et al., 1990; Emtner et al., 1990; Moller et al., 1992; Wang et al., 1992; Moller, 1992; Wang et al., submitted). Furthermore, in 3T3-F442A cells, multiple proteins exhibit GH-dependent increases in tyrosyl phosphorylation. Consistent with activation of JAK2 being required for these phosphorylations, tyrosyl phosphorylation of JAK2/pp121 is simultaneous with or precedes tyrosyl phosphorylation of all the proteins exhibiting GH-dependent tyrosyl phosphorylation, at all GH concentrations tested (this work and Campbell et al., 1993).

Presumably, JAK2 serves as a signaling molecule for GHR by phosphorylating other proteins. Thus far, only two proteins have been identified as likely substrates of JAK2: JAK2 itself and GHR. Studies using truncated GHR indicate that in the cytoplasmic domain of the GHR, at least 1 of the 4 tyrosyl residues most proximal to the membrane is phosphorylated in response to GH (Wang et al., submitted). Studies are underway to identify which of the 4 tyrosines are phosphorylated by JAK2, as well as to identify tyrosines in the C-terminal portion of GHR that might also be phosphorylated. It is important to determine the identity and number of tyrosines phosphorylated in JAK2 and GHR, because these sites are likely to be binding sites for SH2-containing proteins (e.g., phospholipase C-y, p85 phosphatidylinositol-3 kinase, and GTPase-activating protein; Koch et al., 1991) in intracellular signaling pathways.
Signaling pathways involving SH2-containing proteins that bind to phosphorylated JAK2 would be expected to be shared by all ligands that activate JAK2, whereas $\mathrm{SH} 2$ containing proteins that bind to phosphorylated tyrosyl residues in GHR could provide specificity to a signaling mechanism that utilizes a kinase (i.e., JAK2) with the apparent capacity to service more than one receptor (see below).

JAK2 has also been shown to be activated following the binding of EPO to its receptor (Witthuhn et al., 1993). Other data indicate that IL-3, GM-CSF, G-CSF, IFN- $\gamma$, and prolactin also activate JAK2 (Silvennoinen et al., 1993; Witthuhn et al., 1993; O. S. et al., unpublished data; G. S. C. et al., unpublished data). Thus, it appears that JAK2 serves as a kinase for multiple members of the cytokine/hematopoietin receptor family. Since each ligand elicits a separate constellation of responses, kinase activation alone cannot account for specificity. As mentioned above, a set of responses dependent upon phosphorylation of the receptor could provide this specificity. Additionally, specificity could be obtained by interaction between multiple signaling pathways or by the expression of only one receptor type in a particular cell type. This latter mechanism is suggested by the ability of GH, G-CSF, and EPO to stimulate proliferation of IL-3-dependent cells transfected with the cDNA for the appropriate receptor (Fukunaga et al., 1991; Ishizaka-lkeda et al., 1993; Yoshimura et al., 1990).

The commonality of JAK2 activation suggests that there will be shared pathways activated by the ligands that bind JAK2-coupled receptors. Of particular interest for gaining insight into regulation of gene transcription by $\mathrm{GH}$ is a pathway initiated by IFN- $\gamma$. In response to IFN- $\gamma$, the 91 kd protein of the ISGF-3 (IFN-stimulated gene factor 3) complex undergoes tyrosyl phosphorylation and then translocates to the nucleus, where it binds to DNA at the $\gamma$-activated site (Shuai et al., 1992). Identification of the $90 \mathrm{kd}$ protein phosphorylated in response to $\mathrm{GH}$ (Campbell et al., 1993) as the $91 \mathrm{kd}$ protein of the ISGF-3 complex or a family member would implicate one pathway by which $\mathrm{GH}$ might elicit some of its effects on gene transcription.

\section{Activation of JAK2 by GH}

The exact mechanism by which GH activates JAK2 is not yet known. Earlier studies using an exogenous substrate (poly Glu, Tyr) established that more tyrosine kinase activity is present in a complex with GHR when GHR is prepared from GH-treated cells than from control cells (Stred et al., 1992). The present study suggests that this GHinduced increase in kinase activity results from both an increase in affinity of GHR for JAK2 and an increase in JAK2 activity. JAK2 appears to bind directly to GHR, since only two proteins, migrating with sizes appropriate for $J A K 2$ and GHR, are visualized when highly purified kinaseactive $\mathrm{GH}-\mathrm{GHR}$ complexes are isolated from $\mathrm{GH}$-treated ${ }^{35}$ S-labeled 3T3-F442A fibroblasts by sequential immunoprecipitation using $\alpha \mathrm{PY}$ and then either $\alpha \mathrm{GHR}$ or $\alpha \mathrm{GH}$ (Stred et al., 1992). The mechanism by which GH pro- 
motes association of JAK2 with GHR and JAK2 activation is likely to require dimerization of GHR, since GH-induced tyrosyl phosphorylation of cellular proteins appears to require dimerization of GHR (Silva et al., 1993). An important role for receptor dimerization in signaling via JAK2 is further suggested by work relating JAK2 activation to EPO receptor dimerization discussed by Witthuhn et al. (1993).

On the basis of these findings, we hypothesize that the binding of GH by GHR results in the formation of a ligandbound GHR dimer capable of binding JAK2. Recruitment of JAK2 leads to the formation of a GH-GHR-JAK2 complex, stimulation of JAK2 tyrosine kinase activity, and tyrosyl phosphorylation of JAK2, GHR, and presumably other proteins. Whether activated JAK2 is present only in a complex with GHR or can dissociate from GHR and phosphorylate proteins that are physically distant from GHR is currently being investigated. Also under investigation is the possibility that GHR can form complexes with kinases other than, or in addition to, JAK2. Obvious candidate kinases include other members of the JAK family. In 3T3-F442A and IM-9 cells, respectively, JAK1 and Tyk2 do not appear to associate with GHR to the same extent as JAK2. However, they or other as yet unidentified JAK kinases may do so in other cell types or under different physiological conditions.

It will be intriguing to determine whether the interactions between JAK2 and the receptors for IL-3, EPO, GM-CSF, G-CSF, prolactin, and IFN- $\gamma$, like the interaction between JAK2 and GHR, is ligand dependent. In the accompanying paper (Witthuhn et al., 1993), JAK2 from either EPOstimulated or unstimulated cells is reported to bind to a fusion protein composed of glutathione S-transferase and the cytoplasmic domain of the EPO receptor. This suggests that JAK2 may be constitutively associated with some of the receptors capable of activating JAK2.

In summary, the experiments presented in the present paper, in combination with the similar findings for the EPO receptor presented in the accompanying paper and other work with the receptors for IL-3, GM-CSF, G-CSF, prolactin, and IFN- $\gamma$ (Silvennoinen et al., 1993; Witthuhn et al., 1993; O. S. et al., unpublished data; G. S. C. et al., unpublished data), suggest that the activation of JAK2 kinase activity by $\mathrm{GH}$ and EPO by a mechanism involving a JAK2receptor complex may be a prototype for signaling by many members of the cytokine/hematopoietin family receptors. The finding that GHR shares an important and early signaling molecule with other members of the cytokine/hematopoietin receptor family suggests that $\mathrm{GH}$, IL-3, EPO, prolactin, GM-CSF, G-CSF and IFN- $\gamma$ are likely to share some signaling pathways. However, specificity could still be achieved, since phosphorylation of each receptor offers signaling capabilities unique to each ligand. The variable expression of individual receptors, the potential presence of only a subset of all possible signaling pathways in different.cell types, and regulation of the signaling molecules in these pathways by other stimuli permits an additional level of specificity. This finding is likely to lead to the identification of new actions for GH as well as for these other cytokines.

\section{Experimental Procedures}

\section{Materials}

Stocks of 3T3-F442A and CHO4 cells were kind gifts of H. Green (Harvard University, Cambridge, MA) and G. Norstedt (Karolinska Institute, Novum, Sweden), respectively. Recombinant human GH (hGH) was provided by Eli Lilly. Platelet-derived growth factor (recombinant human BB) and recombinant epidermal growth factor came from Collaborative Research. Recombinant insulin-like growth factor 1 was a gift of Kabi/Pharmacia. Triton X-100 (Surfact-Amps X-100) came from Pierce Chemical Company, aprotinin and leupeptin from Boehringer Mannheim, recombinant protein A-agarose from Repligen, [ $\left.\gamma-{ }_{-32}{ }^{32}\right]$ ATP ( $6000 \mathrm{Ci} / \mathrm{mmol}$ ) from New England Nuclear Corporation, and the enhanced chemiluminescence detection system from Amersham Corporation.

\section{Antlbodies}

aGH (NIDDK-anti-hGH-IC3, lot C11981) came from the National Institute of Diabetes and Digestive and Kidney Diseases/National Hormone and Pituitary Program, University of Maryland School of Medicine (Baltimore). aPY-Shafer was a gift of Dr. J. A. Shafer (Merck, Sharp, and Dohme Research Laboratory, West Point, PA; Pang et al., 1985), and $\alpha P Y-4 G 10$ was purchased from UBI. aJAK2 was prepared in rabbits against a synthetic peptide corresponding to the hinge region between domains 1 and 2 of murine JAK2 (amino acids 758-776; Silvennoinen et al., 1993). aJAK1 was prepared against a synthetic peptide to a corresponding region in murine JAK1 (amino acids 785-804; Silvennoinen et al., 1993). One $\alpha$ GHR ( $\alpha$ GHR-C1) was prepared in rabbits against a fusion protein composed of glutathione S-transferase fused to the cytoplasmic domain of the cloned mouse liver GHR and affinity purified using immobilized GHR cytoplasmic domain (L. S. A. et al., unpublished data). A second $\alpha$ GHR ( $\alpha$ GHBP-poly), kindly provided by Dr. W. R. Baumbach (American Cyanamid, Princeton, NJ), was produced in rabbits using recombinant rat GH-binding protein produced in Escherichia coli (Sadeghi et al., 1990). aTyk2 was a gift of Dr. J. J. Krolewski (Columbia University, New York). $\alpha$ GLUT-1 was prepared in rabbits using band 4.5 purified from human erythrocytes. it recognizes both human and rodent GLUT-1 (Tai et al., 1990),

\section{Immunoprecipitation and Western Blotting}

Cells were grown to confluence and deprived of serum overnight as described previously (Wang et al., 1993). Cells were incubated for the indicated times with hormone or growth factor as indicated at $37^{\circ} \mathrm{C}$ in $95 \%$ air, $5 \% \mathrm{CO}_{2}$, rinsed with three changes of ice-cold $10 \mathrm{mM}$ sodium phosphate (pH 7.4), $137 \mathrm{mM} \mathrm{NaCl}, 1 \mathrm{mM} \mathrm{Na}_{3} \mathrm{VO}_{4}$, and scraped in lysis buffer (50 mM Tris [pH 7.5], 0.1\% Triton X-100, $137 \mathrm{mM} \mathrm{NaCl}$, $2 \mathrm{mM}$ EGTA, $1 \mathrm{mM} \mathrm{Na} \mathrm{VO}_{4}, 1 \mathrm{mM}$ phenylmethylsulfonyl fluoride, 10 $\mu \mathrm{g} / \mathrm{ml}$ aprotinin, and $10 \mu \mathrm{g} / \mathrm{ml}$ leupeptin) on ice. Cell lysates were centrifuged at $12,000 \times \mathrm{g}$ for $10 \mathrm{~min}$, and the resulting supernatants were incubated on ice for $90 \mathrm{~min}$ with the indicated antibody. Immune complexes were collected on protein A-agarose during a 30-60 min incubation at $8^{\circ} \mathrm{C}$, washed three times with wash buffer $(50 \mathrm{mM}$ Tris [pH 7.5], $0.1 \%$ Triton X-100, $137 \mathrm{mM} \mathrm{NaCl}, 2 \mathrm{mM}$ EGTA) and boiled for $5 \mathrm{~min}$ in a mixture (80:20) of lysis buffer and SDS-polyacrylamide gel electrophoresis (SDS-PAGE) sample buffer (250 mM Tris [pH 6.8], $10 \%$ SDS, $10 \% \beta$-mercaptoethanol, $40 \%$ glycerol). Unfractionated lysates were brought to the same final concentrations of Tris, SDS, $\beta$-mercaptoethanol, and glycerol and boiled for $5 \mathrm{~min}$. The immunoprecipitates and lysates were subjected to SDS-PAGE followed by Western blot analysis with the indicated antibody (1:5000 dilution unless noted otherwise) using the enhanced chemiluminescence detection system (Campbell et al., 1993). In some experiments, the proteins were dissociated from the immune complexes and then reimmunoprecipitated before analysis by Western blot.

\section{Dissociation and Reimmunoprecipitation of} immune Complexes

The immune complexes from the initial immunoprecipitation were washed once with $50 \mathrm{mM}$ Tris, $137 \mathrm{mM} \mathrm{NaCl}$ (pH 7.5), brought to a final concentration of $0.75 \%$ SDS, $2 \% \beta$-mercaptoethanol, $100 \mathrm{mM}$ DTT, $100 \mu \mathrm{g} / \mathrm{ml}$ aprotinin, and $100 \mu \mathrm{g} / \mathrm{ml}$ leupeptin by addition of an equal volume of a $2 \times$ concentrated stock, and then boiled for $5 \mathrm{~min}$. 
The eluted proteins were diluted 10-fold with lysis buffer. A portion was removed, mixed (80:20) with SDS-PAGE sample buffer, and boiled for $5 \mathrm{~min}$. The remaining sample was incubated with the second antiserum on ice for $60-90 \mathrm{~min}$ and with protein A-agarose at $8^{\circ} \mathrm{C}$ for $1 \mathrm{hr}$. The immune complexes were washed three times with lysis buffer and boiled for $5 \mathrm{~min}$ in a mixture (80:20) of wash buffer and SDS-PAGE sample buffer.

\section{Immunoprecipitation for Kinase Assays}

Serum-deprived cells were incubated at $25^{\circ} \mathrm{C}$ in the absence or presence of $30 \mathrm{ng} / \mathrm{ml} \mathrm{hGH}$ for $60 \mathrm{~min}$. The relatively long incubation period, low GH concentration, and low temperature were used to maximize the in vitro incorporation of ${ }^{32} \mathrm{P}$ into pp130 and GHR during the kinase assay. Cells were washed with phosphate-buffered saline, solubilized in $25 \mathrm{mM}$ HEPES, $2 \mathrm{mM} \mathrm{Na}_{3} \mathrm{VO}_{4}, 0.1 \%$ Triton X-100, $0.5 \mathrm{mM}$ DTT, 1 $\mathrm{mM}$ phenylmethylsulfonyl fluoride, $10 \mu \mathrm{g} / \mathrm{ml}$ aprotinin, $10 \mu \mathrm{g} / \mathrm{ml} \mathrm{leu}$ peptin (pH 7.4) (HVT), and centrifuged at $200,000 \times \mathrm{g}$ for $1 \mathrm{hr}$ at $4^{\circ} \mathrm{C}$. Soluble proteins were incubated on ice for $1 \mathrm{hr}$ with either $\alpha \mathrm{GH}$ (1:10,000 dilution), aPY-Shafer ( $15 \mu \mathrm{g}$ per plate of cells), or aJAK2 (1:1,500 dilution) (Carter-Su et al., 1989). Protein A-agarose was added for an additional $1 \mathrm{hr}$ at $8^{\circ} \mathrm{C}$. Immune complexes were washed three times with $50 \mathrm{mM}$ HEPES, $150 \mathrm{mM} \mathrm{NaCl}, 0.1 \%$ Triton X-100, $0.5 \mathrm{mM}$ DTT (pH 7.6) (NHT) and then once with $50 \mathrm{mM}$ HEPES, 100 $\mathrm{mM} \mathrm{NaCl}, 6.25 \mathrm{mM} \mathrm{MnCl}_{2}, 0.1 \%$ Triton X-100, $0.5 \mathrm{mM}$ DTT (pH 7.6) (HNMT)

\section{Sequential Immunoprecipitation with $\alpha P Y$ and $\alpha$ JAK2}

Proteins immobilized on $\alpha P Y$-protein A-agarose complexes were transferred to a small plastic column and equilibrated for $5 \mathrm{~min}$ with $10 \mathrm{mM}$ p-nitrophenyl phosphate, $20 \mu \mathrm{g} / \mathrm{ml}$ aprotinin, $20 \mu \mathrm{g} / \mathrm{ml}$ leupeptin in HNMT (eluting buffer). Phosphoproteins were then eluted with 180 $\mu$ l of eluting buffer. aJAK2 (1:200 dilution) was added, and the mixture was incubated on ice for $1 \mathrm{hr}$. Protein A-agarose and $0.7 \mathrm{ml}$ of HNMT containing $20 \mu \mathrm{g} / \mathrm{ml}$ aprotinin, $20 \mu \mathrm{g} / \mathrm{ml}$ leupeptin (phosphorylation buffer) was added, and incubation continued at $8^{\circ} \mathrm{C}$ for $1 \mathrm{hr}$. Immune complexes were washed three times with NHT and once with phosphorylation buffer.

\section{In Vitro Kinase Assay and Phosphoamino Acid Analysis}

Proteins immobilized on $\alpha \mathrm{JAK} 2$ or $\alpha \mathrm{GH}$ were mixed with $95 \mu \mathrm{l}$ of phosphorylation buffer. $\left[\gamma^{32}\right.$ P]ATP was then added to yield a final concentration of $10 \mu \mathrm{M} \mathrm{ATP}$ and $5 \mathrm{mM} \mathrm{MnCl}_{2}$. After $10 \mathrm{~min}$ at $30^{\circ} \mathrm{C}$, the reaction was stopped with the addition of $10 \mathrm{mM}$ EDTA in NHT. The immune complexes were washed three times with NHT and once with phosphorylation buffer. ${ }^{32}$ P-labeled proteins were either subjected to a second immunoprecipitation or boiled for $5 \mathrm{~min}$ in SDS-PAGE sample buffer, resolved by SDS-PAGE, and visualized by autoradiography. The phosphoamino acid content of phosphorylated proteins was determined by limited acid hydrolysis using a modification of the procedure of Hunter and Sefton (1980) as described previously (Carter-Su et al. 1989; Stred et al., 1990; Wang et al., 1992).

\section{SDS-PAGE and Densitometry}

Proteins were separated by SDS-PAGE on 3\%-10\% gradient gels (30:0.05 acrylamide:bisacrylamide) as described previously (CarterSu et al., 1989). Densitometry was performed using a Bio-Med Instruments laser scanning densitometer attached to an Apple IIE computer (Bio-Med Instruments Videophoresis II data analysis computer program).

\section{Acknowledgments}

L. S. A. and G. S. C. contributed equally to the work and should both be considered first authors. This work was supported in part by research grants from the National Institutes of Health to C. C.-S. (RO1 DK34171), J. N. I. (RO1-DK42932 and P30 CA21765), and C. Cepko (RO1-EY08064); a grant from the American Lebanese Syrian Associated Charities to J. N. I.; National Research Servlce Award postdoctoral fellowships from the National Institutes of Health to L. S. A. (1F32DK08737) and G. S. C. (1F32-GM14099); and postdoctoral fellowships to $X$. $Y$. from the Helen Hay Whitney Foundation and the Medical Foundation/Charles King Trust. We thank Drs. R. Jove, J. Schwartz, M. Uhler, and C. Cepko for helpful comments.
Received May 6, 1993; revised June 1, 1993.

\section{References}

Bazan, J. F. (1990). Structural design and molecular evolution of a cytokine receptor superfamily. Proc. Natl. Acad. Sci. USA 87, 6934 6938.

Billestrup, N., Moldrup, A., Serup, P., Mathews, L. S., Norstedt, G. and Nielsen, J. (1990). Introduction of exogenous growth hormone receptors augments growth hormone-responsive insulin biosynthesis in rat insulinoma cells. Proc. Natl. Acad. Sci. USA 87, 7210-7214.

Campbell, G. S., Christian, L. J., and Carter-Su, C. (1993). Evidence for involvement of the growth hormone receptor-associated tyrosine kinase in actions of growth hormone. J. Biol. Chem. 268, 7427-7434. Carter-Su, C., Stubbart, J. R., Wang, X., Stred, S. E., Argetsinger, L. S., and Shafer, J. A. (1989). Phosphorylation of highly purified growth hormone receptors by a growth hormone receptor-associated tyrosine kinase. J. Biol. Chem. 264, 18654-18661.

Cheek, D. B., and Hill, D. E. (1974). Effect of growth hormone on cell and somatic growth. In Handbook of Physiology, Volume 4, E. Knobl and W. H. Sawyer, eds. (Washington DC: American Physiological Society), pp. 159-185.

Davidson, M. B. (1987). Effect of growth hormone on carbohydrate and lipid metabolism. Endocrinol. Rev. 8, 115-131.

Emtner, M., Mathews, L. S., and Norstedt, G. (1990). Growth hormone (GH) stimulates protein synthesis in cells transfected with $\mathrm{GH}$ receptor complementary DNA. Mol. Endocrinol. 4, 2014-2020.

Firmbach-Kraft, I., Byers, M., Shows, T., Dalla-Favera, R., and Krolewski, J. J. (1990). Tyk2, prototype of a novel class of non-receptor tyrosine kinase genes. Oncogene 5, 1329-1336.

Fukunaga, R., ishizaka-lkeda, R., Pan, C.-X., Seto, Y., and Nagata, $S$. (1991). Functional domains of the granulocyte colony-stimulating factor receptor. EMBO J. 10. 2855-2865.

Harpur, A. G., Andres, A.-C., Ziemiecki, A., Aston, R. R., and Wilks, A. F. (1992). JAK2, a third member of the JAK family of protein tyrosine kinases. Oncogene $7,1347-1353$

Hunter, T., and Sefton, B. M. (1980). Transforming gene product of Rous sarcoma virus phosphorylates tyrosine. Proc. Natl. Acad. Sci. USA 77, 1311-1315.

Isaksson, O. G. P., Lindahl, A., and Isgaard, J. (1987). Mechanism of the stimulatory effect of growth hormone on longitudinal bone growth Endocrinol. Rev. 8, 426-438.

Ishizaka.lkeda, E., Fukunaga, R., Wood, W. I., Goeddel, D. V., and Nagata, S. (1993). Signal transduction mediated by growth hormone receptor and its chimeric molecules with the granulocyte colonystimulating factor receptor. Proc. Natl. Acad. Sci. USA 90, 123-127. Kaplan, D. R., Hempstead, B., Martin-Zanca, D., Chao, M., and Parada, L. F. (1991). The trk proto-oncogene product: a signal transducing receptor for nerve growth factor. Science 252, 554-558.

Koch, A. A., Anderson, D., Moran, M. F., Ellis, C., and Pawson, T. (1991). SH2 and SH3 domains: elements that control interactions of cytoplasmic signaling proteins. Science 252, 668-674.

Leung, D. W., Spencer, S. A., Cachianes, G., Hammonds, R. G., Collins, C., Henzel, W. J., Barnard, R., Waters, M. J., and Wood, W. I (1987). Growth hormone receptor and serum binding protein: purification, cloning and expression. Nature 330, 537-543.

Levi-Montalcini, R. (1987). The nerve growth factor 35 years later. Science 237, 1154-1162

Moller, C. (1992). Growth hormone regulation of lipid metabolism in cells transfected with rat GH receptor cDNA. In Aspects of the Mechanism of Growth Hormone Action. PhD thesis, Karolinska Institute, NOVUM, Huddinge, Sweden, Section 4 pp. 1-9

Moller, C., Hansson, A., Enberg, B., Lobie, P. E., and Norstedt, G. (1992). Growth hormone induction of tyrosine phosphorylation and activation of mitogen activated protein kinases in cells transfected with rat GH receptor cDNA. J. Biol. Chem. 267, 23403-23408.

Pang, D. T., Sharma, B. R., and Shafer, J. A. (1985). Purification of 
the catalytically active phosphorylated form of insulin receptor kinase by affinity chromatography with 0-phosphotyrosine-binding antibodies. Arch. Biochem. Biophys. 242, 176-186.

Sadeghi, H., Wang, B. S., Lumanglas, A. L., Logan, J. S., and Baumbach, W. R. (1990). Identification of the origin of the growth hormonebinding protein in rat serum. Mol. Endocrinol. 4, 1799-1805.

Schwartz, J., and Carter-Su, C. (1988). Effects of growth hormone on glucose metabolism and glucose transport in 3T3-F442A cells: dependence on cell differentiation. Endocrinology 122, 2247-2256.

Shuai, K., Schindler, C., Prezioso, V. R., and Darnell, J. E., Jr. (1992). Activation of transcription by IFN- $\gamma$ : tyrosine phosphorylation of a 91-kD DNA binding protein. Science 258, 1808-1812.

Silva, C. M., Weber, M. J., and Thorner, M. O. (1993). Stimulation of tyrosine phosphonylation in human cells by activation of the growth hormone receptor. Endocrinology 132, 101-108.

Silvennoinen, O., Witthuhn, B., Quelle, F. W., Cleveland, J. L., Yi, T., and Ihlo, J. N. (1993). Structure of the JAK2 protein tyrosine kinase and its role in IL-3 signal transduction. Proc. Natl. Acad. Sci. USA, in press.

Stred, S. E., Stubbart, J. H., Argetsinger, L. S., Shafer, J. A., and Carter-Su, C. (1990). Demonstration of growth hormone (GH) receptorassociated tyrosine kinase activity in GH-responsive cell types. Endocrinology 127, 2506-2516.

Stred, S. E., Stubbart, J. R., Argetsinger, L. S., Smith, W. C., Shafer, J. A., Talamantes, F., and Carter-Su, C. (1992). Stimulation by growth hormone (GH) of GH receptor-associated tyrosine kinase activity. Endocrinology 130, 1626-1636.

Tai, P.-K. K., Liao, J.-F., Chen, E. H., Dietz, J. J., and Carter-Su, C. (1990). Differential regulation of two glucose transporters by chronic growth hormone treatment of cultured 3T3-F442A adipose cells. J. Biol. Chem. 265, 21828-21834.

Ullrich, A., and Schlessinger, J. (1990). Signal transduction by receptors with tyrosine kinase activity. Cell 61, 203-212.

Velazquez, L., Fellous, M., Stark, G. R., and Pellegrini, S. (1992). A protein tyrosine kinase in the interferon $\alpha / \beta$ signaling pathway. Cell 70, 313-322.

Wang, X., Uhler, M., Billestrup, N., Norstedt, G., Talamantes, F., Nielsen, J. H., and Carter-Su, C. (1992). Evidence for association of the cloned liver growth hormone receptor with a tyrosine kinase. J. Biol. Chem. 267, 17390-17396.

Wang, X., Moller, C., Norstedt, G., and Carter-Su, C. (1993). Growth hormone promoted tyrosyl phosphorylation of a $121-\mathrm{kDa}$ growth hormone receptor-associated protein. J. Biol. Chem. 268, 3573-3579.

Wilks, A. F., Harpur, A. G., Kurban, R. R., Ralph, S. J., Zurcher, G., and Ziemiecki, A. (1991). Two novel protein-tyrosine kinases, each with a second phosphotransferase-related catalytic domain, define a new class of protein kinase. Mol. Cell. Biol. 17, 2057-2065.

Witthuhn, B. A., Quelle, F. W., Silvennoinen, O., Yi, T., Tang, B., Miura, 0. and Ihle, J. N. (1993). JAK2 associates with the erythropoietin receptor and is tyrosine phosphorylated and activated following stimulation with erythropoietin. Cell 74, this issue.

Yoshimura, A., D'Andrea, A. D., and Lodish, H.F.(1990). Friend spleen focus-forming virus glycoprotein gp55 interacts with the erythropoietin receptor in the endoplasmic reticulum and affects receptor metabolism. Proc. Natl. Acad. Sci. USA 87, 4139-4143. 